\title{
Climate change impact on available water resources obtained using multiple global climate and hydrology models
}

\author{
S. Hagemann ${ }^{1}$, C. Chen ${ }^{1}$, D. B. Clark ${ }^{2}$, S. Folwell ${ }^{2}$, S. N. Gosling ${ }^{3}$, I. Haddeland ${ }^{4}$, N. Hanasaki ${ }^{5}$, J. Heinke ${ }^{6}$, \\ F. Ludwig ${ }^{7}$, F. Voss $^{8}$, and A. J. Wiltshire ${ }^{9}$ \\ ${ }^{1}$ Max Planck Institute for Meteorology, Bundesstr. 53, 20146 Hamburg, Germany \\ ${ }^{2}$ Centre for Ecology and Hydrology, Wallingford, UK \\ ${ }^{3}$ School of Geography, University of Nottingham, Nottingham, UK \\ ${ }^{4}$ Norwegian Water Resources and Energy Directorate, Oslo, Norway \\ ${ }^{5}$ National Institute for Environmental Studies, Tsukuba, Japan \\ ${ }^{6}$ Potsdam Institute for Climate Impact Research, Potsdam, Germany \\ ${ }^{7}$ Wageningen University and Research Centre, Wageningen, the Netherlands \\ ${ }^{8}$ Center for Environmental Systems Research, University of Kassel, Kassel, Germany \\ ${ }^{9}$ Met Office Hadley Centre, Exeter, UK \\ Correspondence to: S. Hagemann (stefan.hagemann@zmaw.de)
}

Received: 12 November 2012 - Published in Earth Syst. Dynam. Discuss.: 4 December 2012

Revised: 28 March 2013 - Accepted: 5 April 2013 - Published: 7 May 2013

\begin{abstract}
Climate change is expected to alter the hydrological cycle resulting in large-scale impacts on water availability. However, future climate change impact assessments are highly uncertain. For the first time, multiple global climate (three) and hydrological models (eight) were used to systematically assess the hydrological response to climate change and project the future state of global water resources. This multi-model ensemble allows us to investigate how the hydrology models contribute to the uncertainty in projected hydrological changes compared to the climate models. Due to their systematic biases, GCM outputs cannot be used directly in hydrological impact studies, so a statistical bias correction has been applied. The results show a large spread in projected changes in water resources within the climatehydrology modelling chain for some regions. They clearly demonstrate that climate models are not the only source of uncertainty for hydrological change, and that the spread resulting from the choice of the hydrology model is larger than the spread originating from the climate models over many areas. But there are also areas showing a robust change signal, such as at high latitudes and in some midlatitude regions, where the models agree on the sign of projected hydrological changes, indicative of higher confidence in this ensemble mean signal. In many catchments an increase of avail-
\end{abstract}

able water resources is expected but there are some severe decreases in Central and Southern Europe, the Middle East, the Mississippi River basin, southern Africa, southern China and south-eastern Australia.

\section{Introduction}

Global warming due to increased greenhouse gas emissions leads to changes in the distribution of water resources over many regions, and the global and regional hydrological cycles have been greatly influenced by climate change in the past century (Brutsaert and Palange, 1998; Scanlon et al., 2007; Solomon et al., 2007). Following the greenhouse gas emission scenarios for the 21 st century (Nakicenovic et al., 2000), climate change will cause increased temperatures and changes in precipitation. Estimates of future changes in precipitation, however, are highly uncertain and depend on which climate model is used. Hydrological models have been widely used for assessments of water resources, especially for studying the impacts of climate change. Many studies have tried to assess the impact of climate change on the past and future global water cycle. Multiple climate models are often used so as to consider part of the uncertainty in future 
climate change, but in most cases only one or two hydrological impact models are applied (Gosling and Arnell, 2011; Oki et al., 2003; Nijssen et al., 2001; Döll et al., 2003; Hagemann et al., 2011). Recent studies (Haddeland et al., 2011; Gosling et al., 2011), however, showed that differences between hydrological models are also a major source of uncertainty, and it was suggested that multiple impact models should be used for climate change impact studies (Haddeland et al., 2011). The present study summarizes some of the major outcomes of the European Union project WATCH (WATer and global CHange; http://www.eu-watch.org). Here, climate projections from three state-of-the-art coupled atmosphereocean general circulation models (GCMs), eight global hydrology models (GHMs) and two emission scenarios are used to assess the response of the terrestrial hydrological cycle to climate change and subsequent changes in available water resources. In this respect, this is not only the first study to investigate future water resources using multiple GCMs and GHMs and emission scenarios, but it is also rigorous because eight GHMs were applied, which is by far the most applied in any global climate change impact study thus far. As GCM simulations are significantly affected by systematic errors, and results from a directly forced hydrological simulation will be unrealistic and of little use (Sharma et al., 2007; Hansen et al., 2006), bias-corrected GCM output was used to force the GHMs.

Section 2 describes the GCM-GHM modelling chain and the measures used to analyse the results. Mean changes in large-scale water fluxes and related uncertainties are presented in Sect. 3, where a comparison to water fluxes obtained directly from the GCMs is also included. The impact of climate change on the available water resources is estimated based on the multi-model ensemble results in Sect. 4 . Finally, the results are summarized and discussed in Sect. 5, thereby also highlighting aspects of uncertainty introduced by GHMs.

Note that this study focuses on the impact of climate change alone on water fluxes and resources where direct human influences are not considered. However, land use and water use practices also play a role in the assessment of whether and how strongly human societies are affected in regions with changing water resources. For an estimation of combined anthropogenic and climate change effects, water use and further direct anthropogenic impacts on hydrology have to be taken into account, which will be investigated by Haddeland et al. (2013).

\section{Models and methods}

\subsection{Models}

Three GCMs are used in this study to provide quantitative estimates of future climate projections following the IPCC emission scenarios A2 and B1 (Nakicenovic et al.,
2000): ECHAM5/MPIOM (denoted as ECHAM5 henceforth) of the Max Planck Institute for Meteorology, LMDZ-4 of Institute Pierre Simon Laplace (denoted as IPSL henceforth) and CNRM-CM3 of Centre National de Recherches Météorologiques, Météo-France (denoted as CNRM henceforth). Note that the GCMs chosen belong to different model families and cover some of the range in projected precipitation change from the CMIP3 (Meehl et al., 2007; see also Sect. 5) ensemble (Mason and Knutti, 2011). The selection of GCMs for this study was imposed by the availability of climate model data necessary to force the GHMs. A related analysis of the original GCM results over Europe was provided by Hagemann et al. (2008).

GCMs exhibit a number of significant systematic biases in their ability to simulate key features of the observed climate system (Randall et al., 2007). Despite the biases, the IPCC concludes that there is still considerable confidence that climate models provide credible quantitative estimates of future climate changes (Randall et al., 2007). However, until GCMs perfectly reproduce the current climate, GCM outputs cannot be used directly in hydrological impact studies without some form of bias correction. When uncorrected GCM output is used as input to hydrological simulations, the resulting amount and seasonal distribution of runoff may be far from observations, for example see Haddeland et al. (2012), Wood et al. (2004) and Sharma et al. (2007). Consequently, a statistical bias-correction method (Piani et al., 2010a,b) was applied to the GCM daily land precipitation and mean, and minimum and maximum daily land temperatures. The biascorrection method is based on a fitted histogram equalization function. This function is defined daily, as opposed to earlier published versions in which they were derived yearly or seasonally at best, while conserving properties of robustness and eliminating unrealistic jumps at seasonal or monthly transitions. Bias-correction factors are derived from 1960 to 1999 from observed (Weedon et al., 2011) and original GCM data, and then applied to 1960-2100 simulations (Piani et al., 2010b). For details about the GCM simulations and the biascorrected data, see Hagemann et al. (2011). Although bias correction of climate forcing fields has become a necessary step in climate impact simulations, many recent studies have identified limitations and pitfalls associated with this process (e.g. Haerter et al., 2011; Ehret et al., 2012). However, as stated by Piani and Haerter (2012) the bias correction used here has been applied successfully to regional climate model output over Europe to examine the effects on both simulated climate and extreme hydrological events (Dosio and Paruolo, 2011; Rojas et al., 2011).

Eight GHMs (MPI-HM, LPJmL, WaterGAP, VIC, MacPDM.09, H08, GWAVA and JULES) were used to calculate historic and future water fluxes and simulate the land surface hydrology at a horizontal resolution of $0.5^{\circ}$ (about $50 \mathrm{~km}$ grid spacing). The major model characteristics are listed in Table 1. The GHMs differ in their evapotranspiration and runoff schemes, and the differences in model parameterizations are 
Table 1. Participating models, including their main characteristics (adapted from Haddeland et al., 2011).

\begin{tabular}{|c|c|c|c|c|c|c|}
\hline Model & $\begin{array}{l}\text { Time } \\
\text { step }\end{array}$ & $\begin{array}{l}\text { Meteorological } \\
\text { forcing } \\
\text { variables }^{1}\end{array}$ & $\begin{array}{l}\text { Energy } \\
\text { balance }\end{array}$ & $\begin{array}{l}\mathrm{ET}_{\text {pot }} \\
\text { scheme }^{2}\end{array}$ & $\begin{array}{l}\text { Runoff } \\
\text { scheme }^{4}\end{array}$ & $\begin{array}{l}\text { Snow } \\
\text { scheme }\end{array}$ \\
\hline GWAVA & Daily & $\begin{array}{l}P, T, W, \\
Q, \mathrm{LW}_{\mathrm{n}}, \\
\mathrm{SW}, \mathrm{SP}\end{array}$ & No & $\begin{array}{l}\text { Penman- } \\
\text { Monteith }\end{array}$ & $\begin{array}{l}\text { Saturation } \\
\text { excess/ } \\
\text { beta } \\
\text { function }\end{array}$ & $\begin{array}{l}\text { Degree } \\
\text { day }\end{array}$ \\
\hline H08 & Daily & $\begin{array}{l}R, S, T, \\
W, Q, \\
\mathrm{LW}, \mathrm{SW}, \\
\mathrm{SP}\end{array}$ & Yes & $\begin{array}{l}\text { Bulk } \\
\text { formula }^{3}\end{array}$ & $\begin{array}{l}\text { Saturation } \\
\text { excess/ } \\
\text { beta } \\
\text { function }\end{array}$ & $\begin{array}{l}\text { Energy } \\
\text { balance }\end{array}$ \\
\hline JULES & $1 \mathrm{~h}$ & $\begin{array}{l}R, S, T, \\
W, Q, \\
\mathrm{LW}, \mathrm{SW}, \\
\mathrm{SP}\end{array}$ & Yes & $\begin{array}{l}\text { Penman- } \\
\text { Monteith }\end{array}$ & $\begin{array}{l}\text { Infiltration } \\
\text { excess/ } \\
\text { Darcy }\end{array}$ & $\begin{array}{l}\text { Energy } \\
\text { balance }\end{array}$ \\
\hline LPJmL & Daily & $\begin{array}{l}P, T, \\
\mathrm{LW}_{\mathrm{n}}, \mathrm{SW}\end{array}$ & No & $\begin{array}{l}\text { Priestley- } \\
\text { Taylor }\end{array}$ & $\begin{array}{l}\text { Saturation } \\
\text { excess }\end{array}$ & $\begin{array}{l}\text { Degree } \\
\text { day }\end{array}$ \\
\hline Mac-PDM.09 & Daily & $\begin{array}{l}P, T, W, \\
Q, \mathrm{LW}_{\mathrm{n}}, \\
\mathrm{SW}\end{array}$ & No & $\begin{array}{l}\text { Penman- } \\
\text { Monteith }\end{array}$ & $\begin{array}{l}\text { Saturation } \\
\text { excess/ } \\
\text { beta } \\
\text { function }\end{array}$ & $\begin{array}{l}\text { Degree } \\
\text { day }\end{array}$ \\
\hline MPI-HM & Daily & $P, T$ & No & $\begin{array}{l}\text { Thornth- } \\
\text { waite }\end{array}$ & $\begin{array}{l}\text { Saturation } \\
\text { excess/ } \\
\text { beta } \\
\text { function }\end{array}$ & $\begin{array}{l}\text { Degree } \\
\text { day }\end{array}$ \\
\hline VIC & $\begin{array}{l}\text { Daily/ } \\
3 \mathrm{~h}\end{array}$ & $\begin{array}{l}P, T_{\max }, \\
T_{\min }, W, \\
Q, \mathrm{LW}, \\
\mathrm{SW}, \mathrm{SP}\end{array}$ & $\begin{array}{l}\text { Snow } \\
\text { season }\end{array}$ & $\begin{array}{l}\text { Penman- } \\
\text { Monteith }\end{array}$ & $\begin{array}{l}\text { Saturation } \\
\text { excess/ } \\
\text { beta } \\
\text { function }\end{array}$ & $\begin{array}{l}\text { Energy } \\
\text { balance }\end{array}$ \\
\hline WaterGAP & Daily & $\begin{array}{l}P, T, \\
\mathrm{LW}_{\mathrm{n}}, \mathrm{SW}\end{array}$ & No & $\begin{array}{l}\text { Priestley- } \\
\text { Taylor }\end{array}$ & $\begin{array}{l}\text { beta } \\
\text { function }\end{array}$ & $\begin{array}{l}\text { Degree } \\
\text { day }\end{array}$ \\
\hline $\begin{array}{l}\text { R: rainfall rate, } S \text { : } \\
\text { ximum daily air } \\
\text { ggwave radiation } \\
\text { face pressure. }{ }^{2} \mathrm{I} \\
\text { culating the turbu }\end{array}$ & $\begin{array}{l}\text { fall r } \\
\text { ratur }\end{array}$ & $\begin{array}{l}\text { precipitation (rai } \\
\mathrm{LW}_{\mathrm{n}} \text { : longwave } \mathrm{r}\end{array}$ & $\begin{array}{l}\text { ow disti } \\
\text { perature } \\
\text { in flux ( } 1\end{array}$ & $\begin{array}{l}\text { ed in the r } \\
\text { vind speec } \\
\text { W: shortw }\end{array}$ & $\begin{array}{l}T: \text { air ten } \\
\text { pecific hun } \\
\text { diation flux } \\
\text { ients are us }\end{array}$ & $\begin{array}{l}\text { ture, } T_{\max } \text { : } \\
\text { LW: } \\
\text { vnward), SP: } \\
\text { hen }\end{array}$ \\
\hline
\end{tabular}

to some extent reflected in the forcing variables that are used by each (Table 1). For associated model references and validation of GHM model results using quasi-observational forcing data, see Haddeland et al. (2011). The variability among the GHM results forced with bias-corrected GCM output and associated runoff biases for the control period 1971-2000 are in accordance with the validation shown in Haddeland et al. (2011).

Note that our study focused on the impact of climate change on hydrology, and anthropogenic influences such as water withdrawals and reservoirs were not taken into account in the hydrological simulations.

\subsection{Experimental setup and measures}

Figure 1 presents an overview on the global modelling chain developed and employed within the WATCH project (cf. Sect. 2.1). To evaluate the projected hydrological cycle obtained from the multi-model ensemble, the ensemble means and the spread around these means due to different sources were calculated. For both emission scenarios, transient simulations from 1960-2100 were conducted by the GHMs. For the high emission A 2 scenario, simulations by all 8 GHMs forced by output from the 3 GCMs resulted in 24 different time series for each hydrological variable. For the low emission B1 scenario, 18 simulations were obtained from 6 GHMs (excluding JULES and H08) forced by 


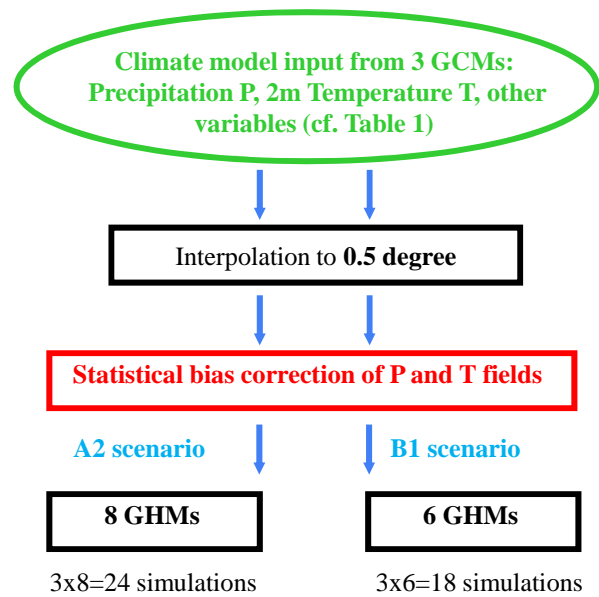

Fig. 1. Global modelling chain in the WATCH project.

3 GCMs. The ensemble mean of each hydrological variable (evapotranspiration and runoff) was calculated for the control (1971-2000) and future (2071-2100) periods, and the changes are expressed for the future relative to the control period.

In this study, uncertainty is reflected by the spread of the model results due to the choice of the GCM (3), GHM (8) or emission scenario (2). For the first two, the spread is calculated from the normalized standard deviation (or coefficient of variation, CV) that is commonly used to express relative differences between models. Here, the spread due to the choice of the GCM is determined by taking the ensemble mean of the $8 \mathrm{GHM}$ results for each GCM, and subsequently calculating the standard deviation among the 3 GCMs. The GHM spread is calculated correspondingly from the standard deviation of the GCM ensemble (3) means for each of the 8 GHMs. For the emissions, the scenario spread is represented by the differences between the ensemble mean results of the high emission scenario A2 and the lower emission scenario B1, obtained from those GHM simulations that were conducted for both scenarios $(6 x \times 3=18)$. As this study focuses on changes in available water resources, associated changes in the main components of the terrestrial water balance are considered, i.e. precipitation (simulated by the GCMs), total runoff and evapotranspiration (simulated by the GHMs forced with bias-corrected GCM data).

\section{Mean changes in large-scale water fluxes and related uncertainties}

\subsection{Results from the GCM-GHM ensemble}

In the following, projected changes are associated with the A2 scenario if not mentioned otherwise. According to the results of the bias-corrected GCM A2 simulations, precipitation is projected to increase by the end of the 21 st century across the higher latitude regions and in parts of the middle latitudes (Fig. 2a). Parts of the Middle East, the Mediterranean region, the southern parts of North America, Africa and Southern Australia will receive less precipitation. These future changes in precipitation show similar patterns to the ensemble of 21 GCM results summarized in the 4th IPCC Assessment Report (Solomon et al., 2007). Noticeable uncertainties in the simulated precipitation change occur over northern Africa, the Indian monsoon region and Himalaya, some northern and western parts of South America, a small area in western Australia, the southern part of North America and over Greenland (Fig. 2b)

Water resources depend strongly on the available runoff, which in the long term is constrained by incoming precipitation and outgoing evapotranspiration (ET). Runoff is projected to decrease over the eastern part of Australia, southern parts of Africa and the US, the north-eastern part of South America, the southern part of Europe, and a large part of the Middle East (Fig. 3a). Largely, the change pattern of runoff follows the ensemble mean change of precipitation (Fig. 2a). This behaviour is similar for the projected mean changes in ET (Fig. 3b), with the noticeable exception that ET also increases in the northern high- and midlatitudes and extends further southwards into the transitional wet regions. This can be observed over south-eastern US, central Europe and eastern Asia.

Although for many large regions around the globe there is generally a large spread of absolute changes predicted by the different model simulations, many models agree on the sign of projected changes (Fig. 3c and d). For runoff, regions with relatively high mean changes are generally those regions where the majority of the 24 GCM-GHM model combinations agree on the sign of change. This indicates that the projected runoff changes expressed by the multi-model mean are robust within the ensemble. The same applies for ET, except for relative changes in the central Amazon and the very dry regions of the Sahara and southern Mexico where there is less agreement between the models.

For both ET and runoff, we estimated whether the largest spread in the projected changes originates from the choice of GCM (Fig. 4a and b), GHM (Fig. 4c and d) or scenario. For ET (Fig. 5a), the uncertainty in the projected changes is largely dominated by the spread due to the choice of the GHM. Especially over high latitude regions, GHMs cause noticeable uncertainty (Fig. 4c) where the spread originating from the GCMs is rather low (Fig. 4a). For runoff, the CV values representing the GCM spread (Fig. 4b) are often comparable to those for the GHM spread (Fig. 4d), even though the GCM spread is larger over many regions of the globe (Fig. 5b). The spread patterns associated with the runoff changes suggest that they are partially affected by the corresponding spreads in the ET changes. But the associated CV values are strongly reduced compared to the $\mathrm{CV}$ of the ET changes, especially over the mid- and low latitudes including Central and Southern Europe. This means that on one 


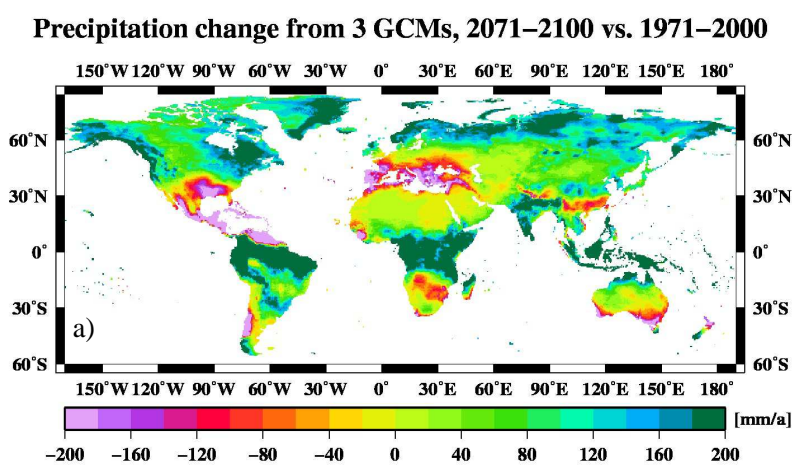

CV of precipitation change from 3 GCMs, 2071-2100 vs. 1971-2000

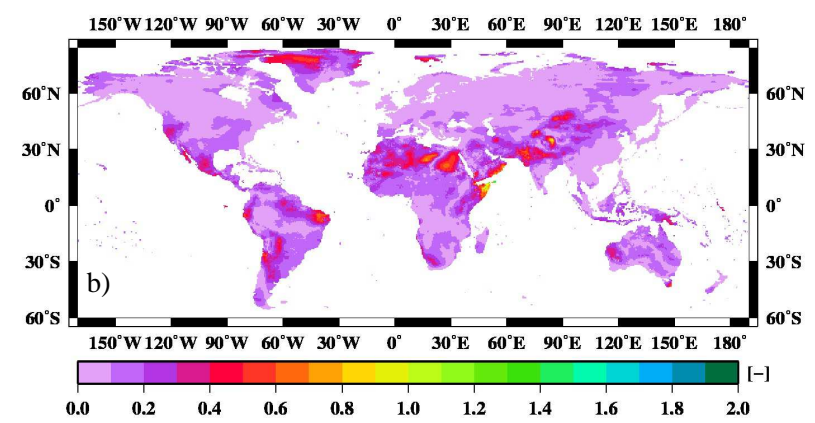

Fig. 2. Annual ensemble mean changes in bias corrected precipitation $\left(\mathrm{mm} \mathrm{a}^{-1}\right.$ ) projected by the three GCMs following the A2 scenario for 2071-2100 compared to 1971-2000 (a) and the CV of these changes from the three GCMs (b).

hand the main spread in runoff changes originates from the choice of the GCM, particularly through the projected precipitation changes (Fig. 2). On the other hand, there are several areas where the runoff spread is dominated by the spread in ET changes that is largely induced by the GHMs, noticeably over the high northern latitudes. Note that in a recent study, which follows a similar model setup as in our study, the GHM runoff spread is dominant over even larger areas (Fig. 1 in Schewe et al., 2013). This can be explained by the fact that we are considering a common time period while Schewe et al. (2013) are comparing model results for a unified global warming $\left(2^{\circ} \mathrm{C}\right.$ above present day) for which the GCM patterns are more similar due to the same amount of warming in the global mean temperature.

We now consider whether the projected changes and associated spreads behave differently in dry (humid) areas where ET tends to be limited primarily by the availability of moisture (energy). These areas are represented by low (high) values of the ensemble mean runoff coefficient (runoff $R$ divided by precipitation $P$ ) for the present-day climate (Fig. 6a). Figure 6b and c show that humid areas expect increases in ET and runoff, while decreases in both variables occur only over some medium wet (e.g. Danube) to dry (e.g. Murray) areas $(R / P<0.6)$. Considering the spreads, it can be noted that for both ET and runoff the
GCM spread tends to be larger for dry areas than for humid areas (Fig. 7a and b). For the GHM spread, there is a less clear tendency, even though some larger $\mathrm{CVs}(\mathrm{CV}>1.7$ for ET, CV $>1.2$ for runoff) only occur over medium wet to dry areas $(R / P<0.5)$.

In the A2 scenario some high- and midlatitude regions show more precipitation and runoff than the B1 scenario (Fig. S1 in the Supplement). In most other areas the projected changes are rather comparable. With regard to ET, most areas show larger values in the future period for the A2 scenario than for the B1 scenario, especially in the Amazon area. ET changes for A2 that are smaller than for B1 are projected over the western part of North America, the southern part of South America and the Middle East. This is an indication of a stronger drying of these regions with increased greenhouse gas concentrations. Noticeable spread due to the choice of scenario largely occurs over areas where the projected ensemble mean A2 change is relatively small. In addition, larger runoff spreads occur over the high northern latitudes, northern USA, some parts of South America and Africa that are comparable and partially larger (see Fig. 5) than those originating from the GCMs or GHMs. Over Africa, southern South America and northern USA, these uncertainties are induced by scenario differences in precipitation that are much larger than those originating from the choice of the GCM. Over Siberia, the scenario spread for runoff seems to be related to the combined effect of scenario spreads in precipitation and ET (Fig. S1 in the Supplement). In most other areas the scenario spread is smaller than those induced by the GCM or GHM.

Figure 8 sets the projected mean A2 changes in relation to the associated spreads over selected large-scale catchments that include the largest rivers on earth as well as some smaller catchments in Europe (Baltic Sea, Danube) and Australia (Murray). Here the spreads are expressed by the absolute standard deviation about $( \pm)$ the respective mean change so as to allow direct comparisons between them. Following Hagemann et al. (2009), a projected change is considered robust if the change is larger than the largest spread. Figure 8 shows that for many catchments the mean A2 change is robust compared to the different spreads, especially for runoff. For several catchments the direction of change is not robust, but is relatively well constrained (larger than half of the largest spread), i.e. Baltic Sea, Mississippi and Nile for runoff, and Amazon, Congo, Ganges/Brahmaputra and Nile for ET. Noticeably, the large GCM spread prohibits a constrained runoff change signal over the Ganges/Brahmaputra (runoff) and Parana (runoff and ET) catchments. Also, projected changes are not constrained for the Danube (ET) and Yangtze (runoff) due to low projected mean changes and large GHM spreads. Consistent with Fig. 5, the GHM spread of the ET changes is largest for most of the catchments (except for Mississippi and Parana), while for runoff the GCM spread prevails for 8 of the 12 catchments considered. But for the large area of the 6 largest Arctic rivers as well as for 
ET change from 3 GCMs \& 8 GHMs, 2071-2100 vs. 1971-2000 Runoff change from 3 GCMs \& 8 GHMs, 2071-2100 vs. 1971-2000

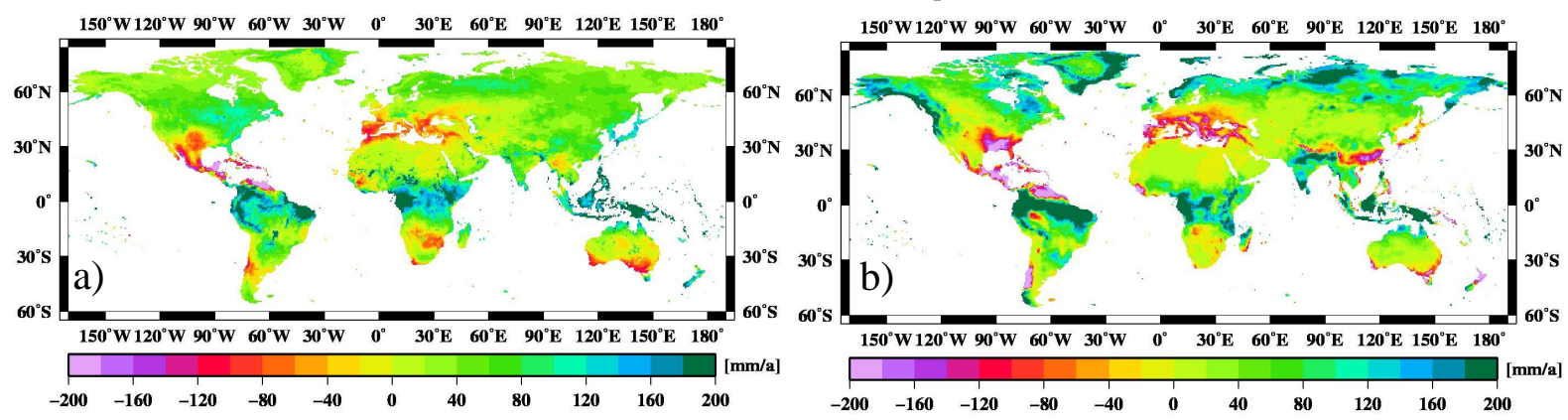

Model difference for ET

Model difference for runoff

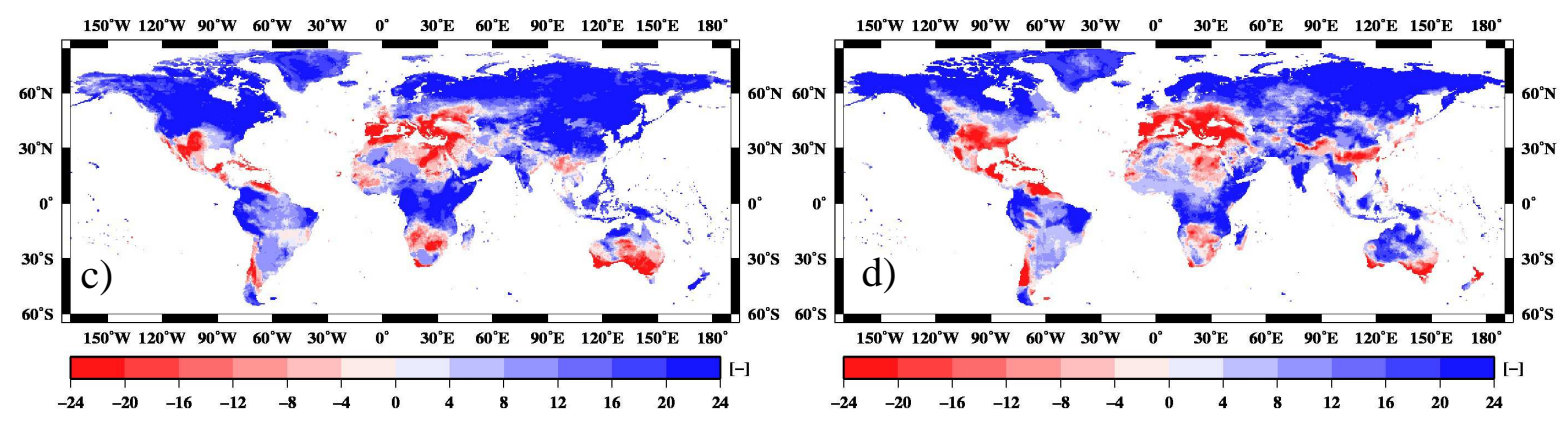

Fig. 3. Ensemble mean results for evapotranspiration (left column) and runoff (right column) from 24 simulations ( 8 GHMs using output from 3 GCMs): mean future changes $\left(\mathrm{mm} \mathrm{a}^{-1}\right.$ ) following the A2 scenario for 2071-2100 compared to 1971-2000 (a, b); number of simulations showing a positive change minus the number showing a negative change (c, $\mathbf{d})$.

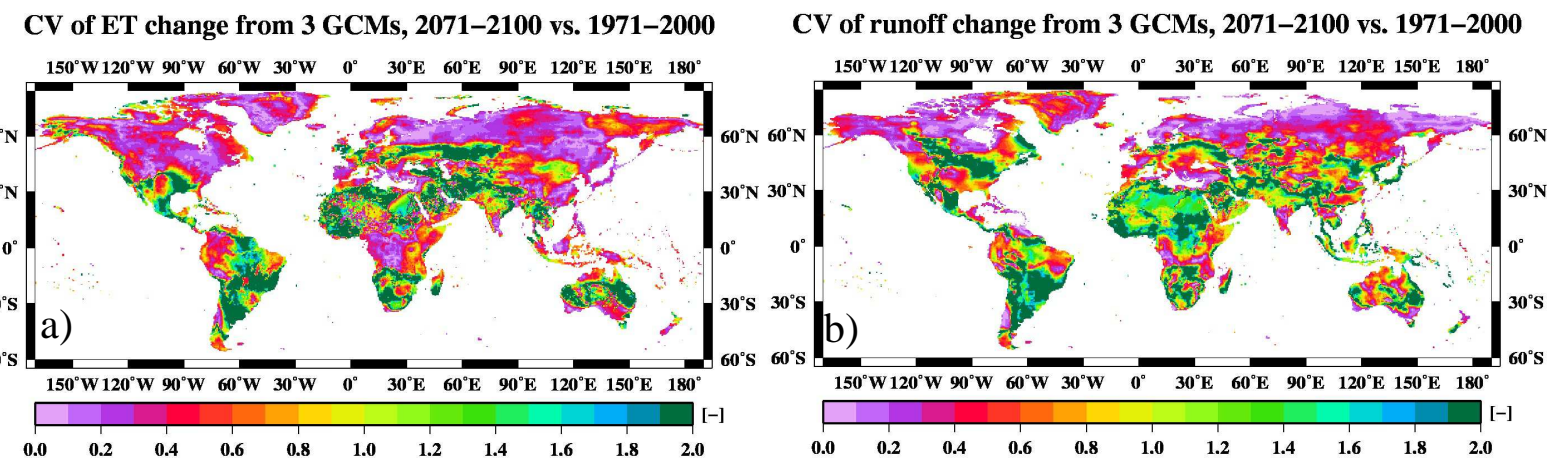

CV of ET change from 8 GHMs, 2071-2100 vs. 1971-2000

CV of runoff change from $8 \mathrm{GHMs,} \mathrm{2071-2100} \mathrm{vs.} \mathrm{1971-2000}$

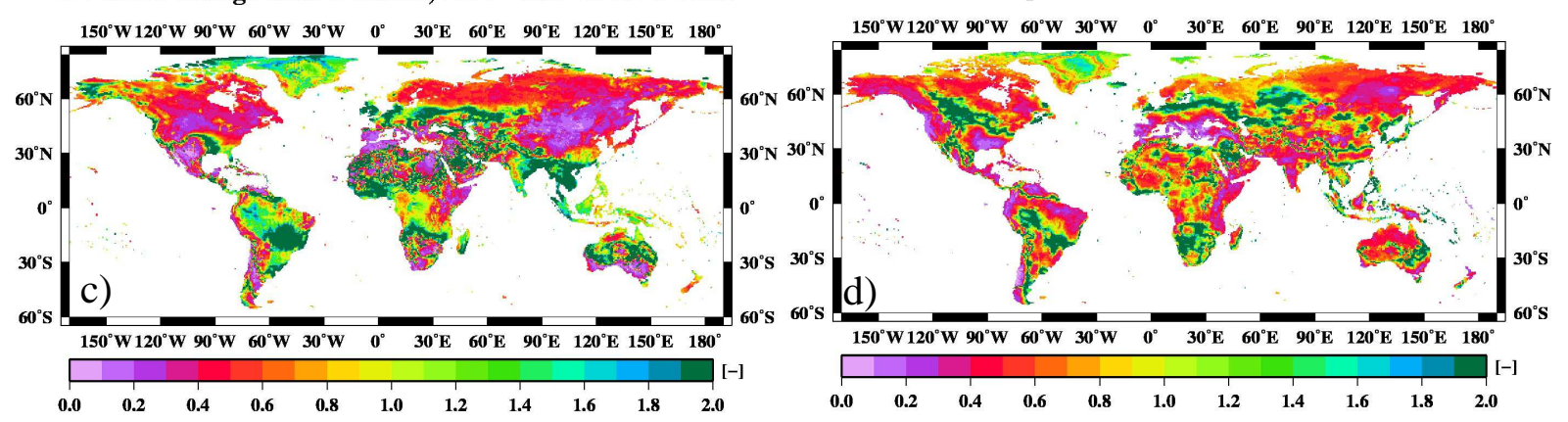

Fig. 4. CVs of evapotranspiration (left column) and runoff (right column) changes shown in Fig. 2 from 3 GCMs (a, b) and from 8 GHMs (c, d). 

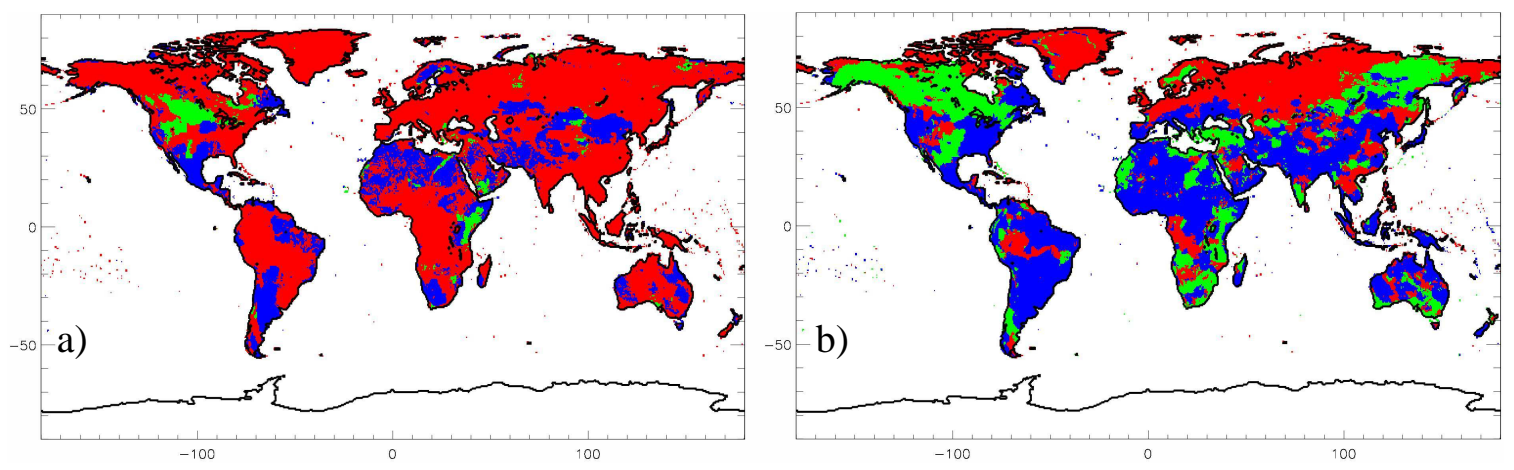

Fig. 5. Areas where the largest spread in projected evapotranspiration (a) and runoff (b) changes (2071-2100 compared to 1971-2000) is due to the choice of the GCM (blue), GHM (red) or scenario (green).

a)

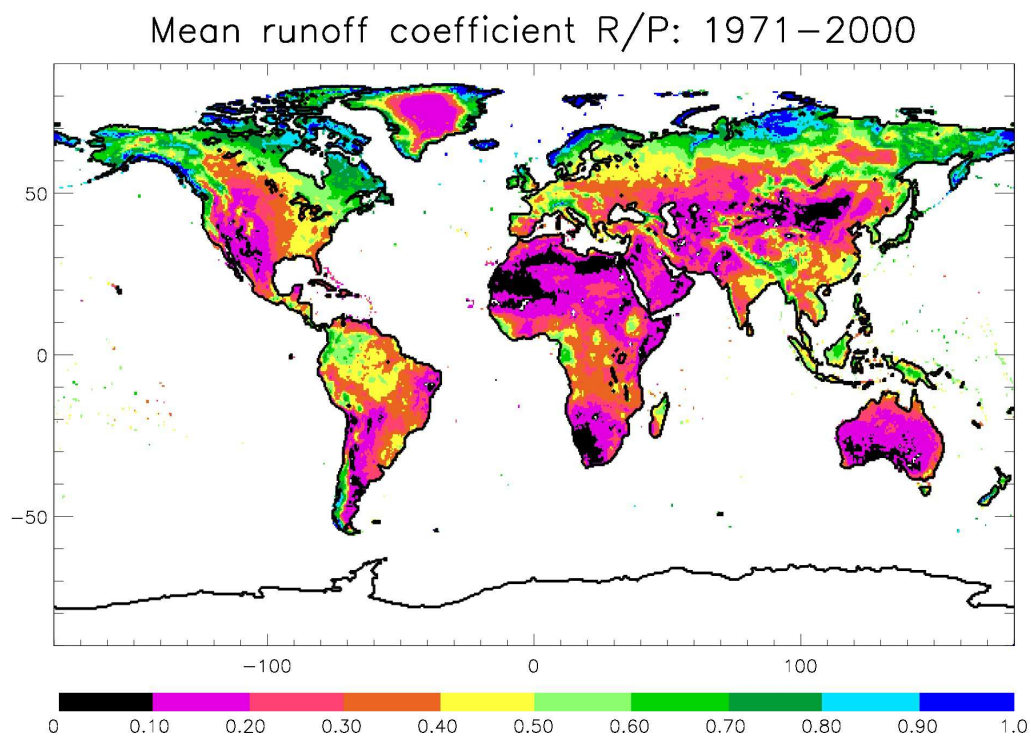

b)

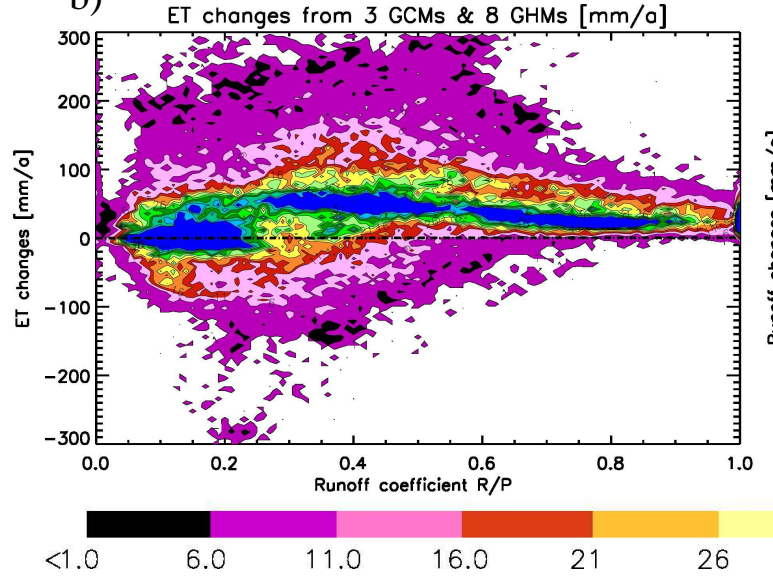

c)

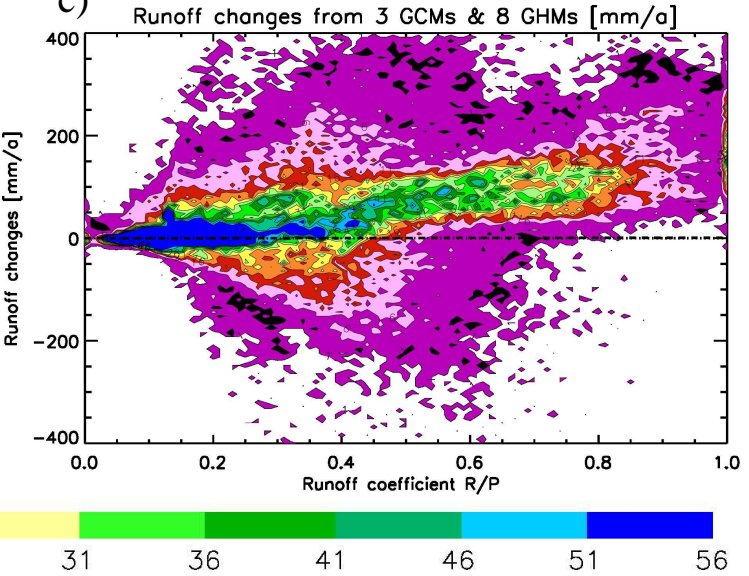

Fig. 6. (a) Ensemble mean runoff coefficient $(R / P)$ for present day (1971-2000), and scatter plots showing how the runoff coefficient relates to the A2 changes in (b) evapotranspiration and (c) runoff obtained from the GCM-GHM ensemble. For (b) and (c), the colours show the number of scatter points. 

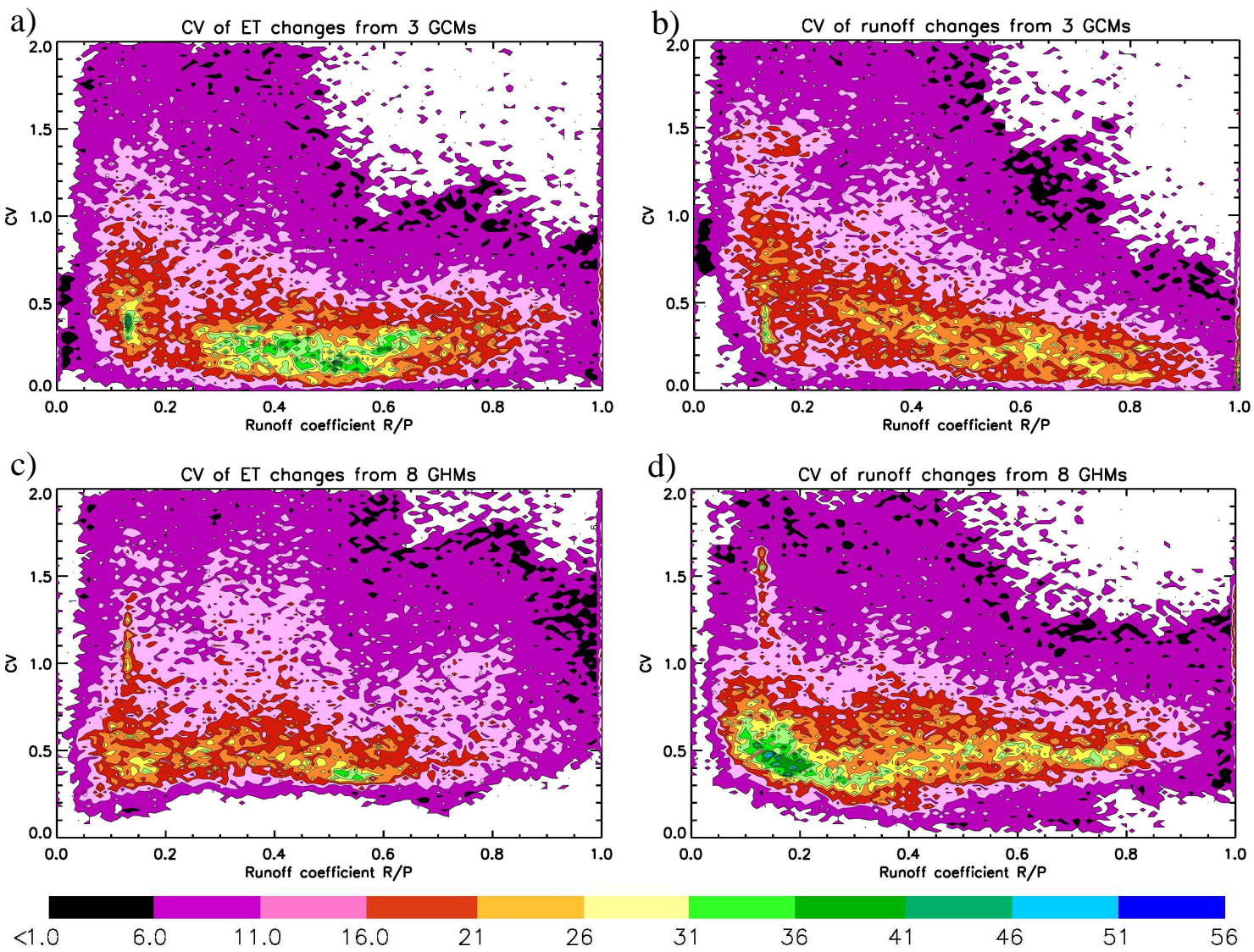

Fig. 7. Scatter plots showing how the ensemble mean runoff coefficient $(R / P)$ for present day relates to the CV of $\mathrm{A} 2$ evapotranspiration (left column) and runoff (right column) changes obtained from 3 GCMs (a, b) and to the CV from 8 GHMs (c, d). The colours show the number of scatter points.

the catchments of Amur, Baltic Sea and Yangtze, the GHM spread is largest, demonstrating the impact of uncertainties in the projected ET changes on the runoff changes over the high- and some midlatitude regions. The scenario spread is generally the smallest spread, especially for runoff, and it is always smaller than the GHM spread, except for ET in the Murray catchment where it is largest. Catchments where the scenario spread is larger than the GCM spread usually comprise areas where the GCM spread is rather low. It should be noted that only three GCMs were applied in this study, so that the uncertainty due to the choice of the GCM is likely somewhat underrepresented, even though the chosen GCMs cover some of the range in projected precipitation change among the CMIP3models (see Sect. 2.1).

\subsection{Comparison to direct GCM output}

With regard to the projected changes in ET and runoff, it is interesting to compare the results from the GCM-GHM ensemble with the uncorrected climate model output obtained directly from the three GCMs. The projected mean A2 changes and associated spreads among the 3 GCMs are shown in Fig. 9. The large-scale patterns of the mean changes are similar to those for the GCM-GHM ensemble (see Fig. S2a and b in the Supplement and Fig. 3a and b), but the absolute intensity of change is mostly lower in the direct GCM output (Fig. 9a and b). This is supported by Fig. 10, where the intensity of change (decreases and increases) is compared. Here, areas indicating larger changes in the GCM-GHM ensemble exceed areas with larger changes in the original GCM output for both ET and runoff. Areas where the sign of change differs are relatively scarce. In this respect, noticeable larger areas are seen for the runoff changes over Australia and east of the Caspian Sea. Considering average changes over large catchments (Fig. 8), it can be noted that the projected A2 changes from the original GCM output are often significantly lower, up to 50-70\% less, than the respective changes projected by the GCMGHM ensemble. This may partly be due to the small sample of 3 GCMs that, with regard to the calculation of ET and their projected changes, may not cover the full space of possible model solutions.

The spread patterns behave differently than the corresponding mean changes. For both ET and runoff, the spread 


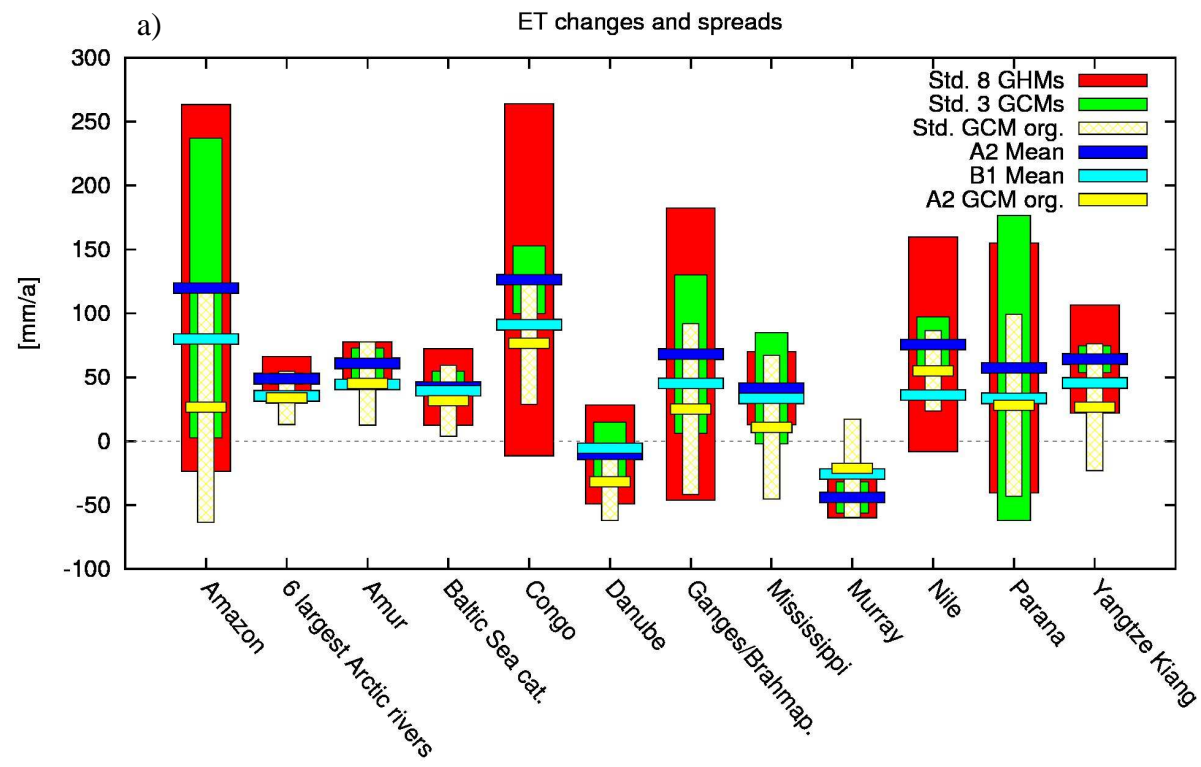

b) Runoff changes and spreads

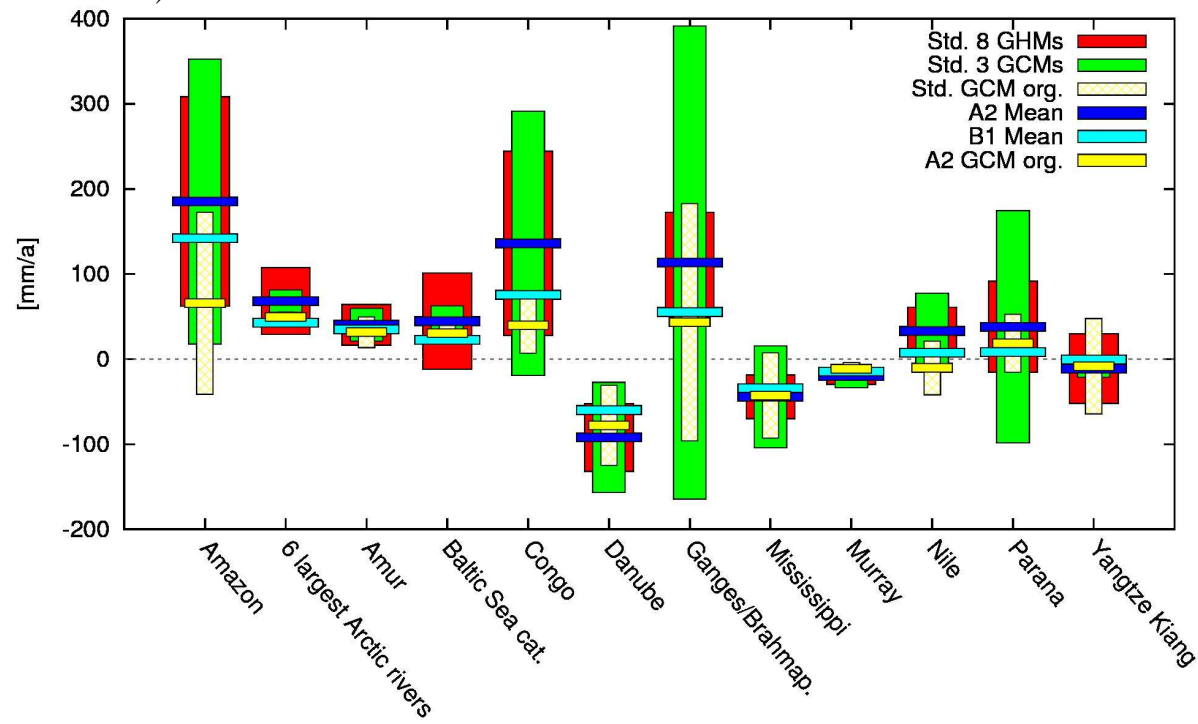

Fig. 8. (a) Mean projected A2 and B1 changes (2071-2100 compared to 1971-2000) in evapotranspiration and associated standard deviations (Std.) due to the choice of the GCM (Std. 3 GCMs) and GHM (Std. 8 GHMs) about the A2 mean (i.e. \pm Std.) over selected large catchments. The mean A2 change and Std. obtained directly from the three original GCM outputs are also shown (A2 GCM org., Std. GCM org.). The 6 largest Arctic rivers comprise the catchments of Mackenzie, Northern Dvina, Yenisei, Ob, Lena and Kolyma. (b) As (a), but for runoff.

in the original (uncorrected) GCM output tends to be larger than the GCM spread in the GCM-GHM ensemble (Fig. 9c and d). This is the case for most parts of the globe (Fig. 11). For ET, the pattern of spread in the original GCM output (Fig. S2c in the Supplement) is rather similar to the spread due to the choice of the GCM in the GCM-GHM ensemble (Fig. 4a) over the Southern Hemisphere and the Tropics, but there are larger differences over the mid- and especially over the high northern latitudes. For runoff, both spreads (Fig. S2d in the Supplement, Fig. 4b) show only some similarities over South America and Central Africa. The higher spread in the original GCM output seems to be a direct result of the GCM-specific biases in precipitation and temperature. In the GCM-GHM ensemble, the bias correction is not only reducing the spread (per definition) in the GCM data for the control period, but also the spread in the climate change signal. Note that the absolute standard deviations are shown in Fig. 8 while the spreads represented by the CV in the Figs. 4, 7, 11 and S2 (in the Supplement) are relative values. Thus, Fig. 8 shows catchment-averaged absolute standard deviations of the original GCM output that are partially smaller than the corresponding standard deviations in the 


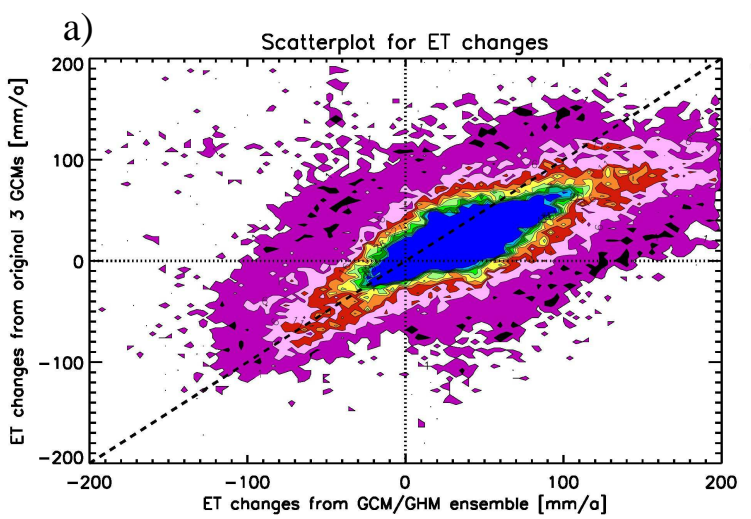

b)

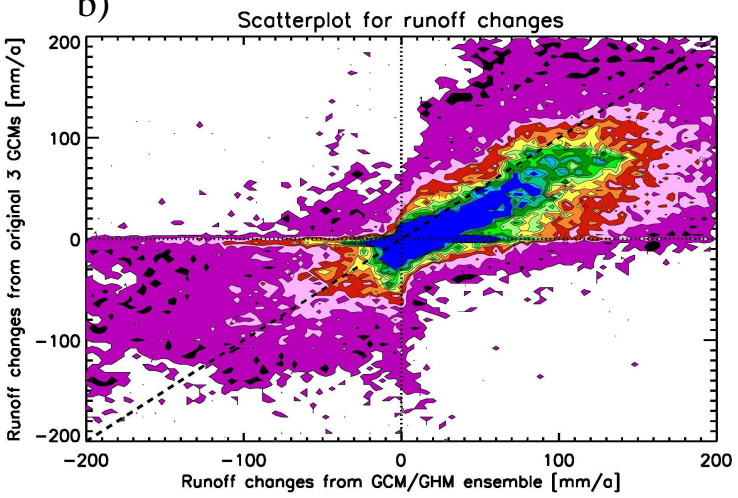

c)

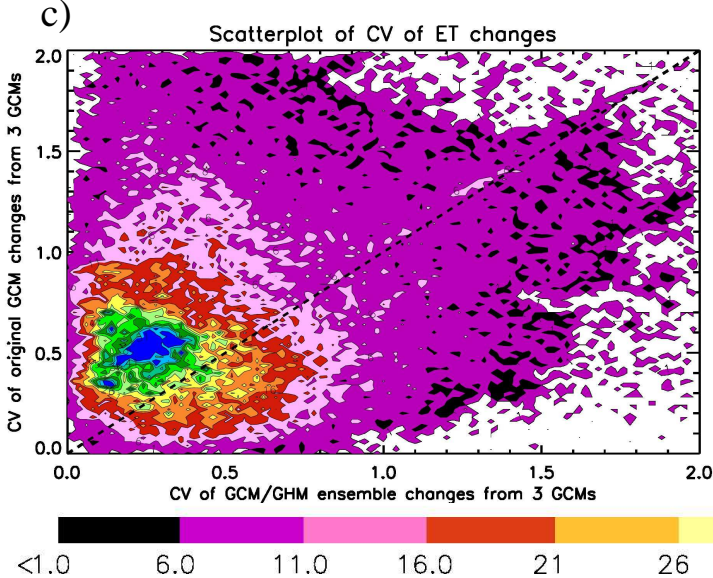

d)

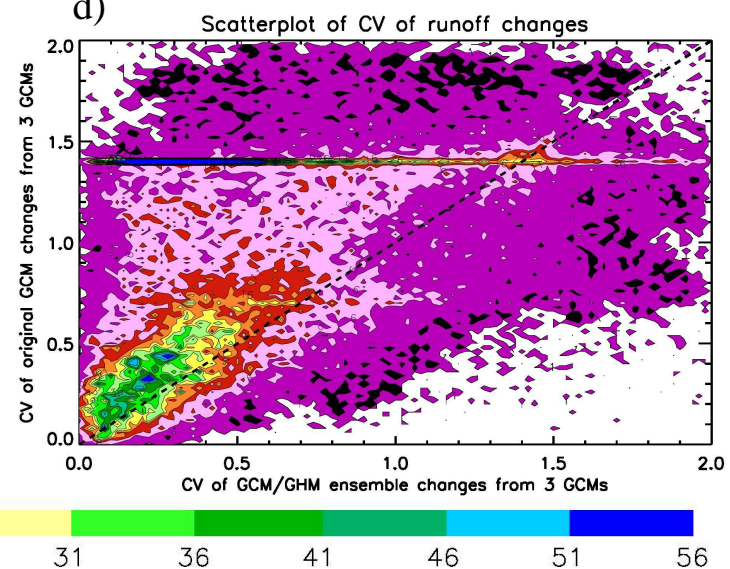

Fig. 9. Scatter plots to compare the results obtained directly from the output of the 3 GCMs to those from the GCM-GHM ensemble: mean future changes ( $\mathrm{mm} \mathrm{a}^{-1}$ ) of evapotranspiration (left column) and runoff (right column) following the A2 scenario for 2071-2100 compared to 1971-2000 (a, b), and the CV of these changes from the 3 GCMs (c, d). The colours show the number of scatter points.
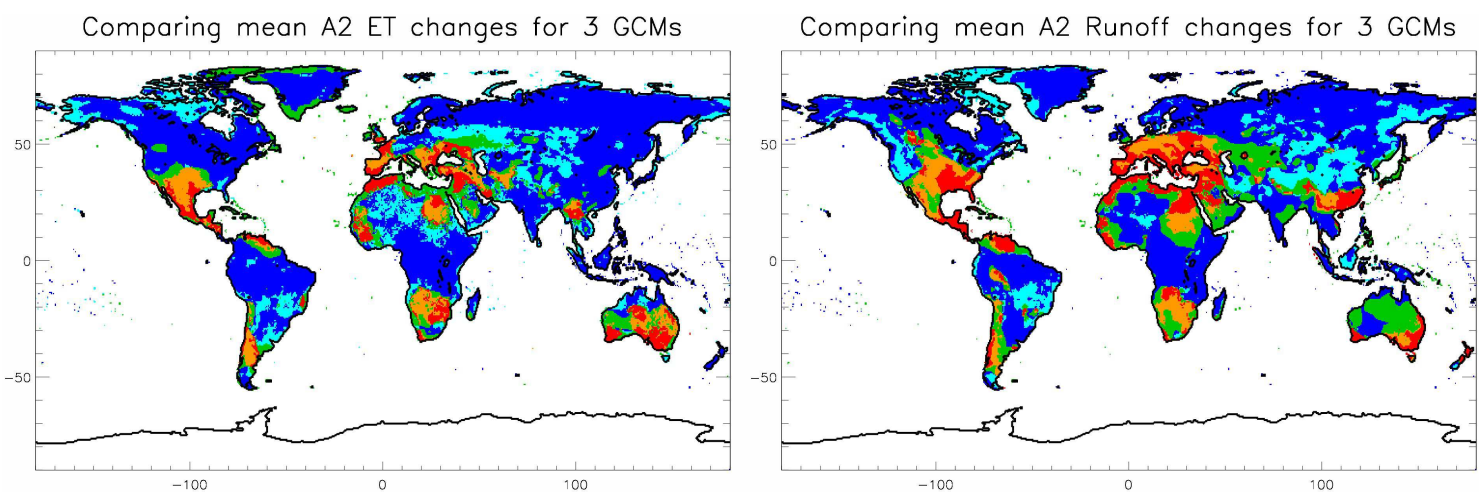

Fig. 10. Comparison of mean A2 evapotranspiration (left panel) and runoff (right panel) changes (2071-2100 compared to 1971-2000) projected by the GCM-GHM ensemble and the original uncorrected GCMs. Areas are indicated where the projected decreases and increases are larger in the GCM-GHM ensemble (red and blue, respectively) than in the original GCM output and vice versa (orange and turquoise, respectively), as well as areas where the sign of projected change differs between them (green).

GCM-GHM ensemble due to the choice of the GCM, especially for runoff. But as the projected mean changes in the direct GCM output are mostly weaker than for the GCM-GHM ensemble (see above in the text), the associated relative values become much larger for the direct GCM output. Thus, the spreads represented by the $\mathrm{CV}$ are often larger for the direct GCM output than their GCM-GHM counterparts (Fig. 11).

This means that even though the projected ET and runoff changes of the original GCM output are fully consistent with the other GCM variables, the associated spread and related 

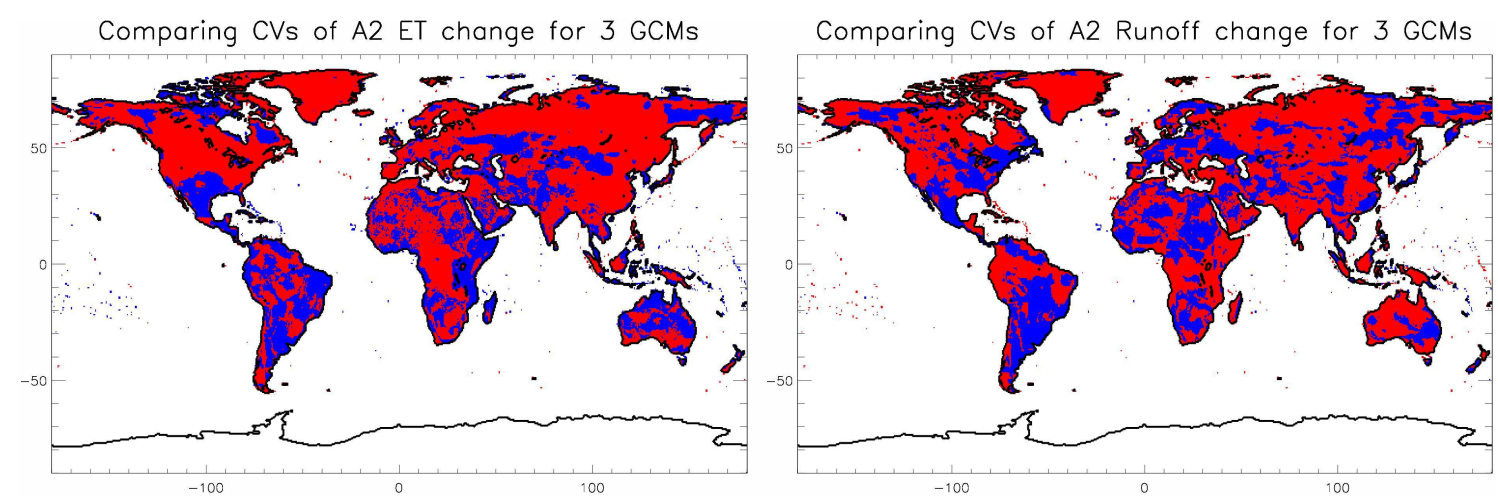

Fig. 11. Comparison of the spreads associated with the mean A2 evapotranspiration (left panel) and runoff (right panel) changes due to the choice of the GCM for the GCM-GHM ensemble and the original uncorrected GCMs. Areas are indicated where the CV is larger for the GCM-GHM ensemble (blue) or for the original GCM output (red).
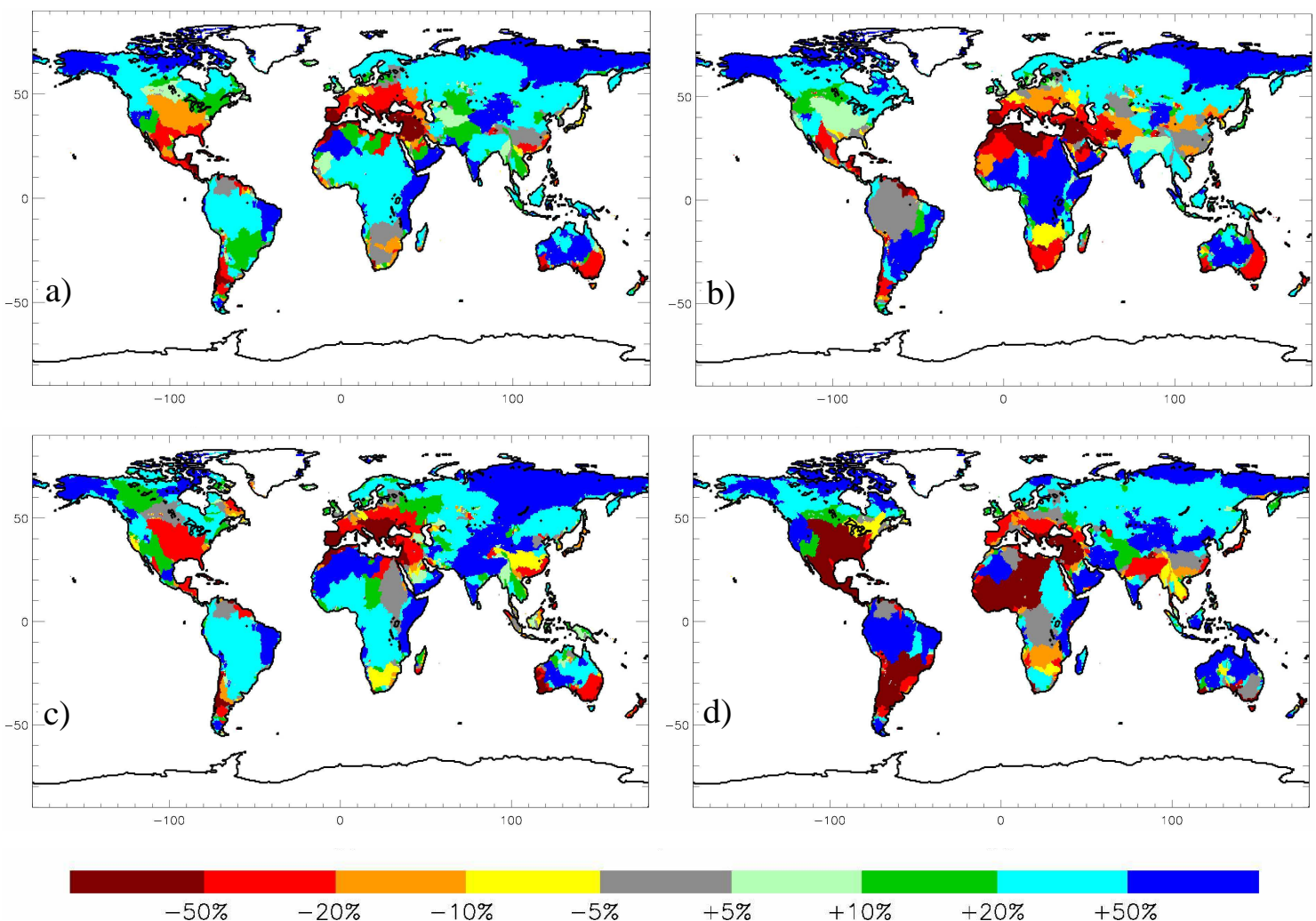

Fig. 12. A2 changes (2071-2100 compared to 1971-2000) in available water resources projected by the 8 GHM ensemble averaged for all 3 GCMs (a), ECHAM (b), CNRM (c) and IPSL (d).

uncertainties in these changes are larger than for the GCMGHM ensemble where the consistency between variables is not necessarily the case due to the bias correction. Thus, the GCM-specific biases in precipitation and temperature lead to larger spreads in the projected changes of terrestrial components of the hydrological cycle. Consequently, these results show a beneficial characteristic of the chosen model setup compared to the direct use of GCM data for impact assess- ment, which can be regarded in the on-going discussion on pros and cons of bias correction (see Sect. 2.1).

\section{Impact on the available water resources}

Based on the results from the 8 GHMs and 3 GCMs, catchment-based maps of changes in available water resources can identify areas that are vulnerable to projected 

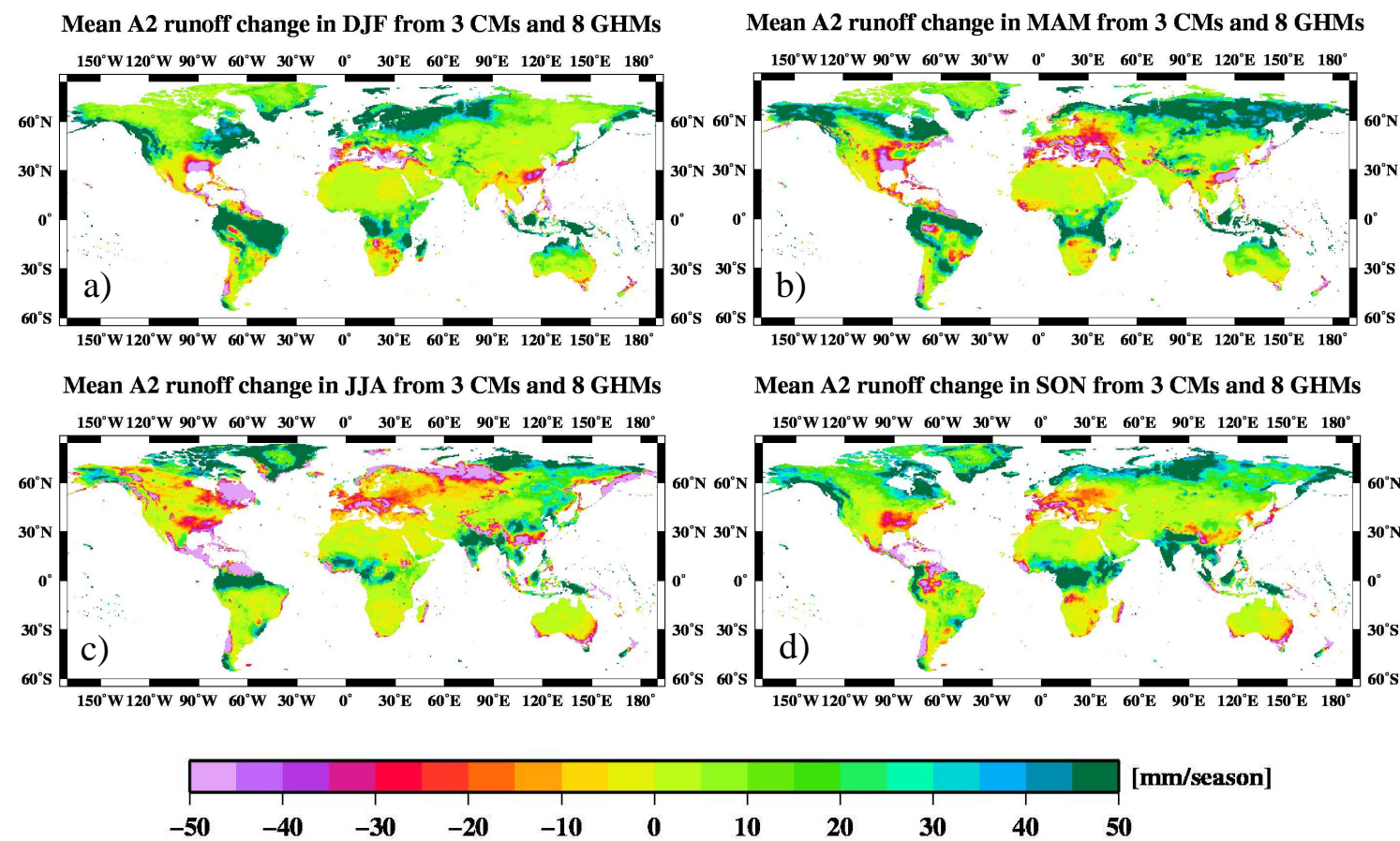

Fig. 13. Ensemble seasonal mean future changes $\left(\mathrm{mm} \mathrm{season}^{-1}\right)$ of runoff from 24 simulations (8 GHMs using output from 3 GCMs) following the A2 scenario for 2071-2100 compared to 1971-2000: (a) boreal winter (DJF), (b) spring (MAM), (c) summer (JJA) and (d) autumn (SON).

climate change with regard to water availability. In this respect, available water resources are defined as the total annual runoff $(R)$ minus the mean environmental water requirements. Using results of Smakhtin et al. (2004), environmental water requirements (EWR) for a catchment were defined as $30 \%$ of the total annual runoff. Assuming EWR will not change significantly in the future, available water resources $(\triangle \mathrm{AW})$ can be estimated as

$$
\begin{aligned}
\Delta \mathrm{AW} & =\left(\left(R_{\mathrm{Scen}}-\mathrm{EWR}\right)-\left(R_{\mathrm{C} 20}-\mathrm{EWR}\right)\right) /\left(R_{\mathrm{C} 20}-\mathrm{EWR}\right) \\
& =\left(R_{\mathrm{Scen}}-R_{\mathrm{C} 20}\right) /\left(R_{\mathrm{C} 20}-\mathrm{EWR}\right) .
\end{aligned}
$$

Here, $R_{\mathrm{C} 20}$ and $R_{\mathrm{Scen}}$ are the mean annual runoff for the current climate (1971-2000) and future scenario (2071-2100) periods, respectively, and $\mathrm{EWR}=0.3 R_{\mathrm{C} 20}$.

Although for runoff there is large uncertainty induced by the choice of GCM (see Figs. 4 and 5), most large catchments (e.g. Amazon, Parana, Nile, Congo, Ganges/Brahmaputra) show an increase in available water resources in the future (Fig. 12). There is some agreement between the 3 GCMs as to where the available water resources are expected to decrease considerably (more than $10 \%$ ). These regions comprise Central, Eastern and Southern Europe, the catchments of the Euphrates/Tigris in the Middle East, Mississippi in North America, Zhu Jiang in southern China, Murray in SE Australia, and Okavango and Limpopo in southern Africa. Here the projections based on the different GCMs largely agree. As only three GCMs are considered, potential future significant reductions in available water resources based only on one of these GCMs cannot be neglected for this impact assessment. Examples of significant decreases are seen in the following large catchments for individual GCMs (Fig. 12): Parana (more than $-50 \%$ for IPSL) and Uruguay (more than $-20 \%$ for IPSL) in South America, Orange (more than $-20 \%$ for ECHAM) in South Africa, Sahel zone comprising Senegal, Niger, Volta and Chari (more than $-50 \%$ for IPSL) and Central and Eastern Asia comprising the Ganges/Brahmaputra (more than $-20 \%$ for IPSL), Indus, Amudarja and Huang $\mathrm{He}$ (more than $-10 \%$ for ECHAM).

The analysis presented above has been conducted on the annual scale, but in some regions available water resources are also affected by seasonal changes. Figure 13 shows the projected changes in runoff per season that can be compared to the annual mean changes shown in Fig. 3b. Regions that might experience a seasonal reduction in runoff that is more severe than in the respective annual mean are potentially affected by a seasonal reduction in available water resources. These regions comprise parts of southern Africa in DJF (Fig. 13a), central eastern South America, Eastern US and Eastern Europe in MAM (Fig. 13b), almost the whole of Europe and western Siberia as well as Western US and southern and western Canada in JJA (Fig. 13c), and north-western South America in SON (Fig. 13d).

It has to be noted that even if the long-term mean annual change in annual water resources may be quite small for some regions, they might be strongly affected by changes 
in interannual variability and the occurrence of droughts. An analysis of these effects is beyond the scope of the present study, but it is an important topic for future studies. In this respect, Prudhomme et al. (2013) investigated the impact of climate change on hydrological droughts.

Climate change has been identified as a major influence on basin water balances. However, land use and water use practices also play a role in the assessment of whether and how strongly human societies are affected in those changing regions. The impact of reduced water availability on different regions also depends on the total water demand and during which season availability will change. These are necessary subjects for future studies.

\section{Conclusions and discussion}

The climate modelling community has a long history of systematic model intercomparison through the climate model intercomparison projects (CMIPs; Meehl et al., 2000). The results of CMIP3 (Meehl et al., 2007) are the basis for the future climate change projections presented in the IPCC 4 th assessment report (Solomon et al., 2007). The results of CMIPs are also used in many climate change impact assessments to quantify the uncertainties originating from climate models and emission scenarios (Gosling et al., 2012; Osborne et al., 2013; Sperna Weiland et al., 2012). Most of the impact assessments, however, only use a single impact model. Here, for the first time a multi-model ensemble comprising multiple global climate (3) and global hydrology models (8) was used to assess future large-scale changes in land surface water fluxes and available water resources. The results presented here clearly show that climate change impacts do not only depend on emission scenarios and climate models, but that different impact models give considerably different results. In some regions the spread of the impact models is larger than that of the climate models.

This ensemble of many different simulations formed the basis for a comparison of the uncertainty in the projected changes originating from the choice of the GCM, the GHM and the emission scenario (B1 and A2). We did not use the direct output of GCMs but instead bias-corrected the GCM time series of precipitation and temperature. Thus, we essentially removed differences between GCMs in those time series in the baseline period, which correspondingly reduces the absolute spread of the GCMs over many regions. Note that the bias correction also adds uncertainty to the projections. Precipitation and temperature are corrected independently. Several studies, such as that of Berg et al. (2009), have shown that daily precipitation shows some scaling with temperature so that future improvements of the bias correction method may be achieved with multivariate approaches (such as presented by Piani and Haerter, 2012) that take these dependencies into account. In addition, GCM variables other than precipitation and temperature are not corrected, which potentially introduces inconsistencies between vari- ables, e.g. between the near surface air humidity and temperature used by some of the GHMs as forcing. However, Haddeland et al. (2012) found that the relative values of projected hydrological change are very similar if other GCM variables are also bias corrected. Thus, it can be assumed that the impact of these inconsistencies is generally rather small. Another uncertainty inherent to the chosen model setup is that the GHM ET does not feed back to the atmosphere, hence it does not impact GCM precipitation or near surface specific humidity.

Despite these uncertainties and inconsistencies, there are currently not many alternatives to this approach for hydrological impact assessments. As mentioned in Sect. 2.1, output from the current generation of GCMs is generally not directly applicable for impact studies, mainly due to the large biases in precipitation and associated biases in surface hydrology (runoff, ET). These biases impact the GCM signals, as do the different GCM parameterizations, and thus lead to uncertainties in projected changes in terrestrial components of the hydrological cycle that are larger than in the model setup presented here. These differences can also lead to different climate change signals which, in the present study, are generally weaker in the uncorrected GCM output, but this may be a characteristic of the chosen 3 GCMs. Note that the usability of direct GCM output may change in the future as developments are also being targeted at improving the water cycle in GCMs and there are some studies in the literature implying there is useful information obtainable directly from GCMs (e.g. Falloon et al., 2011).

Future changes in runoff and ET generally follow the projected changes in the bias-corrected GCM precipitation. These changes comprise projected increases over the high latitudes and some midlatitude regions, while Southern Europe, large parts of the Middle East, southern parts of Africa and the USA, eastern Australia and the north-eastern part of South America will likely experience decreased runoff in the future compared to the control period. These changes are generally consistent with those in previous studies. The results of Haddeland et al. (2011) indicate that, globally averaged, the majority of the interannual variation in precipitation feeds directly through to the runoff and that the evapotranspiration is constrained by other atmospheric factors such as temperature, radiation, and humidity. The same is valid for future changes in runoff and ET, while ET will also be affected by precipitation changes in transitional wet regions where the availability of soil moisture directly affects the evaporative fraction (Seneviratne et al., 2010). In the wet high latitudes (see Fig. 6a) where ET is energy-limited, the precipitation increase (Fig. 2a) is accompanied by a larger warming that leads to more available energy which in turn results in increased ET. Associated with reduced runoff, a significant reduction in available water resources will occur in many catchments on the annual scale, but also for specific seasons. For those regions, the projections based on the different GCMs largely agree. Moreover, when considering 
the large uncertainty associated with the choice of GCM, it is also possible that some regions might be affected by a significant future reduction in available water resources when this is projected only by one of the GCMs.

A deeper analysis of the cause of the projected changes is beyond the scope of the present study as the parameterizations of ET and runoff vary substantially between the GHMs (Table 1 and Haddeland et al., 2011), and the complicated interactions between the various processes make it infeasible to explain the causes of many simulation differences in detail, as noted in previous model intercomparisons (e.g. Koster and Milly, 1997). However, some comments can be made. The results presented here show that the uncertainty in projected changes of land surface water fluxes due to the choice of the GHM cannot be neglected over many regions of the earth. This uncertainly mainly arises from the different model formulations used to represent hydrological processes in the GHMs. Haddeland et al. (2011) found that significant differences between simulations by land surface models (LSMs; models that calculate the land surface energy balance) and "pure" GHMs (without energy balance calculation) for the current climate are partly caused by the snow scheme applied. In that study, which included all the hydrological models that are included in this study, the physically based energy balance approach used by LSMs generally resulted in lower snow water equivalent values than the conceptual degree-day approach used by most GHMs. Some differences in simulated runoff and evapotranspiration are explained by model parameterizations, such as the different treatment of soil moisture and evapotranspiration (Hagemann et al., 2011; Haddeland et al., 2011), although the processes included and parameterizations used are not distinct to either LSMs or pure GHMs. The present study indicates that large differences in the projected changes between the GHMs may be attributed to the different model formulations of evapotranspiration. This becomes especially obvious if the projected changes in evapotranspiration are considered for which the uncertainty related to the choice of the GHM is larger than due to the choice of the GCM over many regions. Uncertainties in projected evapotranspiration changes are generally shown to be due to the choice of the impact model, whereas the choice of the climate model prevails for the future projections of runoff, except for those areas where the evapotranspiration is strongly affecting the future changes in runoff and, thus, the GHM uncertainty is more pronounced.

It should be noted that the response of stomata to $\mathrm{CO}_{2}$ and the related effect on evapotranspiration is neither accounted for by the GCMs nor by the GHMs (except for 1 GHM: LPJmL). It has been shown that the stomatal response leads to a physiological forcing on runoff (e.g. Betts et al., 2007) and is also important for large-scale precipitation over land, so that similar GCM-GHM exercises (see below) with the forthcoming CMIP5 results are recommended to address associated uncertainties. Note also that individual catchment properties can affect the magnitude of hydrological response (see e.g. Arora, 2002; Roderick and Farquhar, 2011; Renner and Bernhofer, 2012). Thus, an application of the framework of Renner and Bernhofer (2012) may be a valuable future extension of our study by linking some of these changes to the aridity index.

The impact of the bias correction (see above) on the projected changes is probably smaller than that caused by the different GHMs. A direct comparison of the simulated GHM changes in ET and runoff from uncorrected and biascorrected GCM output cannot be made for the whole GHM ensemble as most of the GHMs did not produce simulations with the uncorrected GCM output. An indication of the size of the effect can be found by comparing the changes for two of the GHMs in Hagemann et al. (2011) for which, for most of the large catchments considered, the two annual mean GHM climate change signals in ET and runoff differ more than the mean signals obtained with and without bias correction.

Future analyses of global climate change impacts to be used in, for example, the IPCC assessments should not be based on the output of a single impact model. Well coordinated model intercomparison activities are not only needed for climate models but also for the important impacts. Our results show a clear need for intercomparison activities such as ISI-MIP (http://www.isi-mip.org), AgMIP (http://www. agmip.org/) and WaterMIP (Haddeland et al., 2011; http: //www.eu-watch.org/watermip). A major obstacle to the use by policy makers of the results of such model intercomparison projects is the large amount of data and scenarios produced by the different modelling exercises, which have to be reduced to a demonstrative and meaningful gist. There is a need to develop tools and methods which allow for the quantification of uncertainty and assessment of robustness of climate change impacts using multi-model ensembles without generating too much data, and which may be used to demonstrate the associated results in a relatively simple way.

\section{Supplementary material related to this article is available online at: http://www.earth-syst-dynam.net/4/ 129/2013/esd-4-129-2013-supplement.pdf.}

Acknowledgements. This study was supported by funding from the European Union within the WATCH project (contract No. 036946). Andrew Wiltshire was partly supported by the Joint DECC/Defra Met Office Hadley Centre Programme (GS01101). The authors would like to thank Tobias Stacke (MPI-M) for implementing several modifications into MPI-HM, Alexander Schröder (MPI-M) for some data processing and plotting, and Richard Gilham (UKMO) for data transfer and disaggregation work regarding JULES data. The GCM data were obtained from the CERA database at the German Climate Computing Center (DKRZ) in Hamburg. Additional data were thankfully provided by Nathalie Bertrand from IPSL.

Edited by: A. Kleidon 
The service charges for this open access publication have been covered by the Max Planck Society.

\section{References}

Arora, V.: The use of the aridity index to assess climate change effect on annual runoff, J. Hydrol., 265, 164-177, 2002.

Berg, P., Haerter, J. O., Thejll, P., Piani, C., Hagemann, S., and Christensen, J. H.: Seasonal characteristics of the relationship between daily precipitation intensity and surface temperature, J. Geophys. Res., 114, D18102, doi:10.1029/2009JD012008, 2009.

Betts, R. A., Boucher, O., Collins, M., Cox, P. M., Falloon, P. D., Gedney, N., Hemming, D. L., Huntingford, C., Jones, C. D., Sexton, D. M., and Webb, M. J.: Projected increase in continental runoff due to plant responses to increasing carbon dioxide, Nature, 448, 1037-1041, 2007.

Brutsaert, W. and Parlange, M. B.: Hydrologic cycle explains the evaporation paradox, Nature, 396, 30, doi:10.1038/23845, 1998.

Döll, P., Kaspar, F., and Lehner, B.: A global hydrological model for deriving water availability indicators: model tuning and validation, J. Hydrol., 270, 105-134, 2003.

Dosio, A. and Paruolo, P.: Bias correction of the ENSEMBLES high-resolution climate change projections for use by impact models: Evaluation on the present climate, J. Geophys. Res., 116, D16106, doi:10.1029/2011JD015934, 2011.

Ehret, U., Zehe, E., Wulfmeyer, V., Warrach-Sagi, K., and Liebert, J.: HESS Opinions "Should we apply bias correction to global and regional climate model data?", Hydrol. Earth Syst. Sci., 16, 3391-3404, doi:10.5194/hess-16-3391-2012, 2012.

Falloon, P., Betts, R., Wiltshire, A., Dankers, R., Mathison, C., McNeall, D., Bates, P., and Trigg, M.: Validation of river flows in HadGEM1 and HadCM3 with the TRIP river flow model, J. Hydrometeorol., 12, 1157-1180, 2011.

Gosling, S. N. and Arnell, N. W.: Simulating current global river runoff with a global hydrological model: model revisions, validation, and sensitivity analysis, Hydrol. Process., 25, 1129-1145, 2011

Gosling, S. N., Taylor, R. G., Arnell, N. W., and Todd, M. C.: A comparative analysis of projected impacts of climate change on river runoff from global and catchment-scale hydrological models, Hydrol. Earth Syst. Sci., 15, 279-294, doi:10.5194/hess-15279-2011, 2011.

Gosling, S. N., McGregor, G. R., and Lowe, J. A.: The benefits of quantifying climate model uncertainty in climate change impacts assessment: an example with heat-related mortality change estimates, Climatic Change, 112, 217-231, doi:10.1007/s10584011-0211-9, 2012.

Haddeland, I., Clark, D. B., Franssen, W., Ludwig, F., Voß, F., Arnell, N. W., Bertrand, N., Best, M., Folwell, S., Gerten, D., Gomes, S., Gosling, S. N., Hagemann, S., Hanasaki, N., Harding, R., Heinke, J., Kabat, P., Koirala, S., Oki, T., Polcher, J., Stacke, T., Viterbo, P., Weedon, G. P., and Yeh, P.: Multi-model estimate of the global terrestrial water balance: setup and first results, J. Hydrometeorol. 12, 869-884, doi:10.1175/2011JHM1324.1, 2011.

Haddeland, I., Heinke, J., Voß, F., Eisner, S., Chen, C., Hagemann, S., and Ludwig, F.: Effects of climate model radiation, humidity and wind estimates on hydrological simulations, Hydrol. Earth Syst. Sci., 16, 305-318, doi:10.5194/hess-16-305-2012, 2012.

Haddeland, I., Biemans, H., Eisner, S., Fekete, B., Flörke, M., Hanasaki, N., Heinke, J., Ludwig, F., Schewe, J., Stacke, T., Wada, Y., and Wisser, D.: A global multi-model view on water balance alterations caused by human interventions versus climate change, P. Natl. Acad. Sci., submitted, 2013.

Haerter, J. O., Hagemann, S., Moseley, C., and Piani, C.: Climate model bias correction and the role of timescales, Hydrol. Earth Syst. Sci., 15, 1065-1079, doi:10.5194/hess-15-10652011, 2011.

Hagemann, S., Berg, P., Christensen, J. H., and Haerter, J. O.: Analysis of existing climate model results over Europe, WATCH Technical Rep. 7, http://www.eu-watch.org/ publications/technical-reports (last access: 2 May 2013), 2008.

Hagemann, S., Göttel, H., Jacob, D., Lorenz, P., and Roeckner, E.: Improved regional scale processes reflected in projected hydrological changes over large European catchments, Clim. Dynam. 32, 767-781, doi:10.1007/s00382-008-0403-9, 2009.

Hagemann, S., Chen, C., Haerter, J. O., Gerten, D., Heinke, J., and Piani, C.: Impact of a statistical bias correction on the projected hydrological changes obtained from three GCMs and two hydrology models, J. Hydrometeorol., 12, 556-578, doi:10.1175/2011JHM1336.1, 2011.

Hansen, J. W., Challinor, A., Ines, A., Wheeler, T., and Moronet, V.: Translating forecasts into agricultural terms: advances and challenges, Climate Res., 33, 27-41, 2006.

Koster, R. D. and Milly, P. C. D.: The interplay between transpiration and runoff formulations in land surface schemes used with atmospheric models, J. Climate, 10, 1578-1591, 1997.

Masson, D. and Knutti, R.: Climate model genealogy, Geophys. Res. Lett., 38, L08703, doi:10.1029/2011GL046864, 2011.

Meehl, G. A., Boer, G. J., Covey, C., Latif, M., and Stouffer, R. J.: The Coupled Model Intercomparison Project (CMIP), B. Am. Meteorol. Soc., 81, 313-318, 2000.

Meehl, G. A., Covey, C., Delworth, T., Latif, M., McAvaney, B., Mitchell, J. F. B., Stouffer, R. J., and Taylor, K. E.: The WCRP CMIP3 multi-model dataset: A new era in climate change research, B. Am. Meteorol. Soc., 88, 1383-1394, 2007.

Nakicenovic, N., Alcamo, J., Davis, G., de Vries, B., Fenhann, J., Gaffin, S., Gregory, K., Grübler, A., Jung, T. Y., Kram, T., La Rovere, E. L., Michaelis, L., Mori, S., Morita, T., Pepper, W., Pitcher, H., Price, L., Raihi, K., Roehrl, A., Rogner, H.-H., Sankovski, A., Schlesinger, M., Shukla, P., Smith, S., Swart, R., van Rooijen, S., Victor, N., and Dadi, Z.: IPCC Special Report on Emissions Scenarios, Cambridge University Press, Cambridge, UK and New York, NY, USA., 2000.

Nijssen, B., O'Donnell, G. M., Hamlet, A. F., and Lettenmaier, D. P.: Hydrologic sensitivity of global rivers to climatic change, Climatic Change, 50, 143-175, 2001.

Oki, T., Agata, Y., Kanae, S., SaruhashiI, T., and Musiake, K.: Global water resources assessment under climatic change in 2050 using TRIP, Water Resources Systems - Water availability and global change, Proceedings of symposium HS02a held during IUGG2003 at Sapporo, July 2003, IAHS Publ., 280, 124 133, 2003.

Osborne, T., Rose, G. and Wheeler, T.: Variation in the global-scale impacts of climate change on crop productivity due to climate model uncertainty and adaptation, Agr. Forest Meteorol., 170, 
183-194. doi:10.1016/j.agrformet.2012.07.006, 2013.

Piani, C. and Haerter, J. O.: Two dimensional bias correction of temperature and precipitation copulas in climate models, Geophys. Res. Lett., doi:10.1029/2012GL053839, in press, 2012.

Piani, C., Haerter, J. O., and Coppola, E.: Statistical bias correction for daily precipitation in regional climate models over Europe, Theor. Appl. Climatol., 99, 187-192, 2010a.

Piani, C., Weedon, G. P., Best, M., Gomes, S., Viterbo, P., Hagemann, S., and Haerter, J. O.: Statistical bias correction of global simulated daily precipitation and temperature for the application of hydrological models, J. Hydrol., 395, 199-215, $2010 \mathrm{~b}$.

Prudhomme, C., Giuntoli, I., Robinson, E. L., Clark, D. B., Arnell, N. W., Dankers, R., Fekete, B., Franssen, W., Gerten, D., Gosling, S. N., Hagemann, S., Hannah, D. M., Kim, H., Masaki, Y., Satoh, Y., Stacke, T., Wada, Y., and Wisser, D.: Drought in the 21st century: a multi-model ensemble experiment to assess global change, quantify uncertainty and identify "hotspots", P. Natl. Acad. Sci., submitted, 2013.

Randall, D. A., Wood, R. A., Bony, S., Colman, R., Fichefet, T., Fyfe, J., Kattsov, V., Pitman, A., Shukla, J., Srinivasan, J., Stouffer, R. J., Sumi, A., and Taylor, K. E.: Climate Models and Their Evaluation. In: Climate Change 2007: The Physical Science Basis. Contribution of Working Group I to the Fourth Assessment Report of the Intergovernmental Panel on Climate Change, edited by: Solomon, S., Qin, D., Manning, M., Chen, Z., Marquis, M., Averyt, K. B., Tignor, M., and Miller, H. L., Cambridge University Press, Cambridge, United Kingdom and New York, NY, USA, 2007.

Renner, M. and Bernhofer, C.: Applying simple water-energy balance frameworks to predict the climate sensitivity of streamflow over the continental United States, Hydrol. Earth Syst. Sci., 16, 2531-2546, doi:10.5194/hess-16-2531-2012, 2012.

Roderick, M. and Farquhar, G.: A simple framework for relating variations in runoff to variations in climatic conditions and catchment properties, Water Resour. Res., 47, W00G07, doi:10.1029/2010WR009826, 2011.

Rojas, R., Feyen, L., Dosio, A., and Bavera, D.: Improving panEuropean hydrological simulation of extreme events through statistical bias correction of RCM-driven climate simulations, Hydrol. Earth Syst. Sci., 15, 2599-2620, doi:10.5194/hess-15-25992011, 2011.
Scanlon, T. S., Caylor, K. K., Levin, S. A., and Rodriguez-Iturbe, I.: Positive feedbacks promote power-law clustering of Kalahari vegetation, Nature, 449, 209-212, 2007.

Schewe, J., Heinke, J., Gerten, D., Haddeland, I., Arnell, N. W., Clark, D., Dankers, R., Eisner, S., Fekete, B., Colón-González, F. J., Gosling, S., Kim, H., Liu, X., Masaki, Y., Portmann, F. T., Satoh, Y., Stacke, T., Tang, Q., Wada, Y., Wisser, D., Albrecht, T., Frieler, K., Piontek, F., Warszawski, L., and Kabat, P. :Multi-model assessment of water scarcity under climate change, P. Natl. Acad. Sci., submitted, 2013.

Seneviratne, S. I., Corti, T., Davin, E. L., Hirschi, M., Jaeger, E. B., Lehner, I., Orlowsky, B., and Teuling, A. J.: Investigating soil moisture-climate interactions in a changing climate: A review, Earth-Sci. Rev., 99, 125-161, doi:10.1016/j.earscirev.2010.02.004, 2010.

Sharma, D., Das Gupta, A., and Babel, M. S.: Spatial disaggregation of bias-corrected GCM precipitation for improved hydrologic simulation: Ping River Basin, Thailand, Hydrol. Earth Syst. Sci., 11, 1373-1390, doi:10.5194/hess-11-1373-2007, 2007.

Smakhtin, V., Revenga, C., and Döll, P.: A Pilot Global assessment of environmental water requirements and scarcity, Water Int., 29, 307-317, 2004.

Solomon, S., Qin, D., Manning, M., Marquis, M., Averyt, K., Tignor, M. M. B., Miller Jr., H. L., and Chen, Z. (Eds.): Climate Change 2007: The Physical Science Basis, Cambridge University Press, Cambridge, 996 pp., 2007.

Sperna Weiland, F. C., van Beek, L. P. H., Kwadijk, J. C. J., and Bierkens, M. F. P.: Global patterns of change in discharge regimes for 2100, Hydrol. Earth Syst. Sci., 16, 1047-1062, doi:10.5194/hess-16-1047-2012, 2012.

Weedon, G. P., Gomes, S., Viterbo, P., Shuttleworth, W. J., Blyth, E., Österle, H., Adam, J. C., Bellouin, N., Boucher, O., and Best, M.: Creation of the WATCH forcing data and its use to assess global and regional reference crop evaporation over land during the twentieth century, J. Hydrometeorol., 823-848, 12, doi:10.1175/2011JHM1369.1, 2011.

Wood, A. W., Leung, L. R., Shridhar, V., and Lettenmaier, D. P.: Hydrologic implications of dynamical and statistical approaches to downscaling climate outputs, Climatic Change, 62, 189-216, 2004. 